\title{
Proposing a New Mixture Statistical Distribution Exponential - Kumaraswamy
}

\author{
Mohammed Qadoury Abed \\ Assistant Professor \\ Al-Mansour University College \\ Elaf Bahaa Alwan \\ Assistant Lecturer \\ Wasit University \\ Prof. Abbas Lafta Kneehr \\ Wassit University \\ College of Admin \& Econ
}

\begin{abstract}
In general, statistical distributions are divided into two types: probability distributions and complex probability Distributions. In this study, a new probabilistic model is used for the three-dimensional (exponential) curve. We have also discussed its mathematical properties such as probability density function, probability function Diagram, cumulative distribution function, reliability function, and risk function are stated. We have used the maximum likelihood method to estimate the proposed the parameter of the model. The most important conclusions are: the maximum likelihood method has shown itself as one of the best methods, we have observed that the reliability function is a decreasing function, by the theoretical definition, the more the sample sizes increase the reliability decreases and composite distributions are better than other distributions.
\end{abstract}

Keywords: Exponential, Kumaraswamy, Mixture, Distribution, Reliability, Complex, Density, Function, Cumulative, Probability

\section{1 - Introduction}

In recent years, there has been a need for the use of complex distributions, and many studies have referred to these distributions. In $2003^{(15)}$, the researchers (Nassar, Fathy), have studied the mathematical properties of the new model found by them the exponential weibull distribution. In $2009^{(7)}$, the researchers (Souza et al.) presented a research on the generalized exponential data. In addition by using estimation methods, they studied the mathematical properties of probability distribution and estimated model parameters. In 2011 , researchers de Pascoa, Ortega and Cordeiro ${ }^{(10)}$ studied the Kumaraswamy generalized gamma distribution in terms of its mathematical properties, its parameters and practical application of the survival analysis. Al - Saaray ${ }^{(5)}$ in 2011 , conducted a comparison between Bayes Approach method and maximum likelihood method of estimating the reliability function. In 2012, Al - Bayaty ${ }^{(2)}$ conducted a study comparing the methods of estimating the reliability of mixture exponential distribution. The researchers ${ }^{(9)}$ Cordeiro, Nadarajah and Ortega studied in 2012 the mathematical properties of the Kumaraswamy Gumbel distribution. Al - Kadim and Boshi ${ }^{(4)}$ studied in 2013 the exponential pareto distribution with practical application. The Kumaraswamy Geometric distribution studied in $2014^{(6)}$ by the researchers Akinsete, Famoye and Lee. To apply the model, Rodriguez and Silve presented ${ }^{[16]}$ in 2015 a study on the four exponential properties of the Exponential Kumaraswamy - exponential distribution, in which they studied several structural characteristics, including the inversion, the hazard function, the mean, the deviations, and , the Renyi function Entropy, using the maximum possible method (mle) is used. Then the model that they would arrive at was reached would be good if a real data are used. In 2016, Al-Dariei ${ }^{[3]}$ used a threedimensional composite probability model (exponential-weibull) and four estimation methods for the sake of comparison. It was found that the best method of estimation was the maximum likelihood method.. 


\section{2 - Exponential Distribution: ${ }^{(11)}$}

The exponential distribution of probability distributions plays an important role in the theory of the reliability of different systems.

This distribution is distinguished from other distributions in the sense that the risk function is a constant quantity. Lets us have $(\mathrm{x})$ of the actual variables. The probability density function is:

$$
\mathrm{f}(\mathrm{x}, \lambda)=\lambda \exp ^{-\lambda \mathrm{x}} \quad ; \lambda>0, \quad \mathrm{x}>0
$$

$\lambda$ : Represents the distribution parameter

Thus, the cumulative distribution function will be as follows:

$$
\mathrm{F}(\mathrm{X})=1-\mathrm{e}^{-\lambda \mathrm{x}}
$$

\section{3 - Kumaraswamy Distribution $[1,8,12,13,14]$}

This distribution is a continuous probability distribution set over the period [1.0], is similar to the beta distribution, but it is much simpler to be used in simulations. This distribution has two parameters $(\alpha, \beta)$.

Therefore, the probability density function (p.d.f) for the Kumaraswamy

Distribution is as follows:

$$
f(x, \alpha, \beta)=\alpha \beta x^{\alpha-1}\left(1-x^{\alpha}\right)^{\beta-1} \quad 0<x<1
$$

Where $(\alpha, \beta)$ distribution parameters .

The cumulative function (c.d.f) is:

\section{4 - Reliability:}

$$
F(x, \alpha, \beta)=1-\left(1-x^{\alpha}\right)^{\beta} \quad 0 \leq x \leq 1
$$

$$
R(t)=1-F(t) \rightarrow=1-\int_{0}^{t} f(t) d t
$$

$\mathrm{t}$ :

$\mathrm{R}$

$$
\mathrm{f} \quad(\mathrm{t}): \quad \text { Probability }
$$

$\mathrm{F}(\mathrm{t})$ : Cumulative Density Function (CDF). random

time.

function.

$$
\text { Density }
$$

Reliability

Function

(PDF).

\section{5 - Complex Probability Model (The Exponential Kumaraswamy Distribution):} The relevant literature concerned with the estimation of the reliability function on single probability distributions, whether they are continuous or discontinuous. However, in many cases, these distributions cannot be used. This has led to the use of new type of distributions called " Beta - Pareto, beta - gamma, gamma - normal, exponential - weibull) and others. These distributions are a special case of the well - known, distributions, they use the failure time in the reliability field. A complex probabilistic model

$$
F(E-k)=\int_{0}^{\frac{1}{1-F(x)}} f(x, \lambda) d(x) \quad X>0
$$

$\mathrm{F} \quad(\mathrm{x})$ is the aggregate function of a Kumaraswamy Distribution which is equal

$$
F(x, \alpha, \beta)=1-\left(1-x^{\alpha}\right)^{\beta} \quad 0 \leq x \leq 1
$$

Where $\mathrm{f}(\mathrm{x})$ represents the probability density function for exponential distribution

$$
\mathrm{f}(\mathrm{x}, \lambda)=\lambda \exp ^{-\lambda \mathrm{x}} \quad ; \lambda>0, \quad \mathrm{x}>0
$$

The cumulative distribution function of the new compound probability model is as follows:

$$
\begin{gathered}
\mathrm{F}_{\mathrm{E}-\mathrm{K}}(\mathrm{x} ; \alpha, \mathrm{B}, \lambda)=\int_{0}^{\frac{1}{1-\left[1-\left(1-\mathrm{X}^{\alpha}\right)^{\mathrm{B}}\right]}} \lambda \exp ^{-\lambda \mathrm{x}} \mathrm{d}(\mathrm{x}) \\
\mathrm{F}_{\mathrm{E}-\mathrm{K}}(\mathrm{x} ; \alpha, \mathrm{B}, \lambda)=\left[1-\exp ^{-\lambda\left(\left(1-\mathrm{X}^{\alpha}\right)^{-\mathrm{B}}\right)}\right]
\end{gathered}
$$

From equation (8) the probability density function of the proposed model can be reached as follows:

$$
\mathrm{f}_{\mathrm{E}-\mathrm{K}}(\mathrm{x} ; \alpha, \mathrm{B}, \lambda)=\frac{\mathrm{dF}_{\mathrm{E}-\mathrm{K}}(\mathrm{x} ; \alpha, \mathrm{B}, \lambda)}{\mathrm{dx}}
$$


$\therefore \mathrm{f}_{\mathrm{E}-\mathrm{K}}(\mathrm{x} ; \alpha, \mathrm{B}, \lambda)=\left[(\alpha \mathrm{B} \lambda)\left(1-\mathrm{X}^{\alpha}\right)^{-\mathrm{B}-1}\left(\mathrm{X}^{\alpha-1}\right) \exp ^{-\lambda\left(\left(1-\mathrm{X}^{\alpha}\right)^{-\mathrm{B}}\right)}\right], \quad \mathrm{x}>0$

\section{The properties of the proposed new distribution:}

a - Density Function (p.d.f)

(1). $\mathrm{f}(\mathrm{x}) \geq 0, \forall \mathrm{x}$

(2). $\quad \int_{0}^{\infty} \mathrm{f}_{E-K}(\mathrm{x}) \mathrm{dx}=1$

Figure (1) shows that the Figure of the p.d.f for the proposed mixture distribution is Kurtosis from one side ( left ) and that the red color indicates the function of the p.d.f where the parameter values for the model $(\lambda=0.5, \alpha=$ $1, B=2)$, the black color indicates the form of the function when $(\lambda=0.5, \alpha=3, B=3)$ and blue color indicates the form of the function when $(\lambda=1, \alpha=2, B=2)$.

Figure (1): shows the function of p.d.f

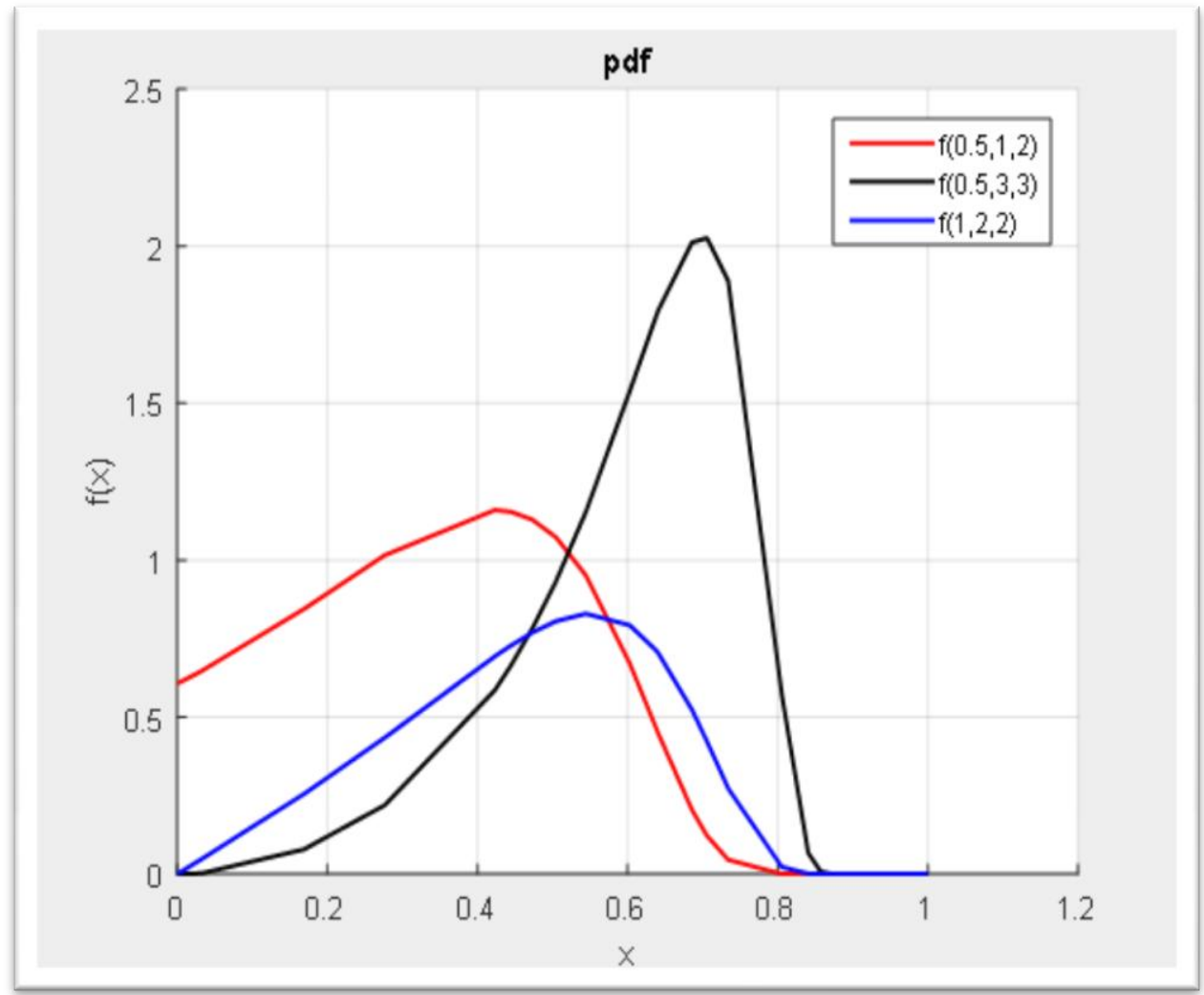

\section{b - The cumulative distribution function (c.d.f):}

$$
\begin{aligned}
& \mathrm{F}_{\mathrm{E}-\mathrm{k}}(\mathrm{x} ; \alpha, \mathrm{B}, \lambda)=\int_{0}^{\mathrm{x}} \mathrm{f}(\mathrm{u}) \mathrm{du} \\
& \mathrm{F}_{\mathrm{E}-\mathrm{k}}(\mathrm{x} ; \alpha, \mathrm{B}, \lambda)=\int_{0}^{\mathrm{x}}(\alpha \mathrm{B} \lambda)\left(1-\mathrm{u}^{\alpha}\right)^{-\mathrm{B}-1}\left(\mathrm{u}^{\alpha-1}\right) \exp ^{-\lambda\left(\left(1-\mathrm{u}^{\alpha}\right)^{-\mathrm{B}}\right)} \mathrm{d}(\mathrm{u}) \\
& \mathrm{F}_{\mathrm{E}-\mathrm{k}}(\mathrm{x} ; \alpha, \mathrm{B}, \lambda)=\left[\exp ^{-\lambda}-\exp ^{-\lambda\left(\left(1-\mathrm{x}^{\alpha}\right)^{-\mathrm{B}}\right)}\right]
\end{aligned}
$$

Figure (2) shows that the Figure of the c.d.f for the proposed mixture distribution is increasing and that the red color indicates the function of the c.d.f where the parameter values for the model $(\lambda=0.5, \alpha=1, B=2)$, the black color indicates the form of the function when $(\lambda=0.5, \alpha=3, \mathrm{~B}=3)$ and the blue color indicates the form of the function when $(\lambda=1, \alpha=2, B=2)$. 
Figure (2): shows the function of c.d.f

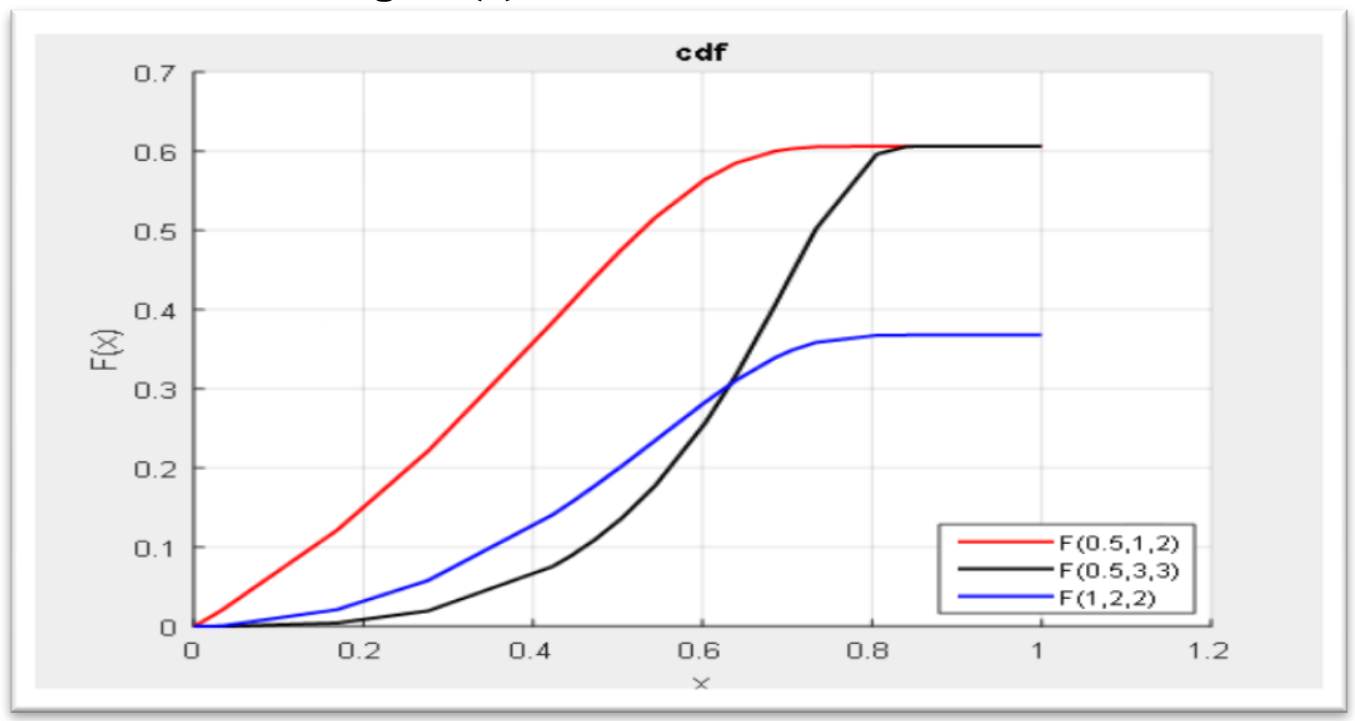

\section{c - Hazard function:}

$$
\begin{aligned}
& h(t)=\frac{f_{t}}{R_{E-K}(t)} \\
& h(t)=\frac{(\alpha B \lambda)\left(1-t^{\alpha}\right)^{-B-1}\left(t^{\alpha-1}\right) \exp ^{-\lambda\left(\left(1-t^{\alpha}\right)^{-B}\right)}}{1-\left[\exp ^{-\lambda}-\exp ^{-\lambda\left(\left(1-t^{\alpha}\right)^{-B}\right)}\right]}
\end{aligned}
$$

\section{d - Reliability function:}

$\mathrm{R}(\mathrm{t})=1-\mathrm{F}(\mathrm{t})$

$\mathrm{R}(\mathrm{t})=1-\left[\exp ^{-\lambda}-\exp ^{-\lambda\left(\left(1-\mathrm{x}^{\alpha}\right)^{-B}\right)}\right]$

Figure (3) shows that the Figure of the Reliability function for the proposed mixture distribution is a decreasing function and that the red color indicates the function of the Reliability function where the parameter values for the model $(\lambda=0.5, \alpha=1, B=2)$, the black color indicates the form of the function when $(\lambda=0.5, \alpha=3, B=$ 3 ) and the blue color indicates the form of the function when $(\lambda=1, \alpha=2, B=2)$.

Figure (3): shows the reliability function

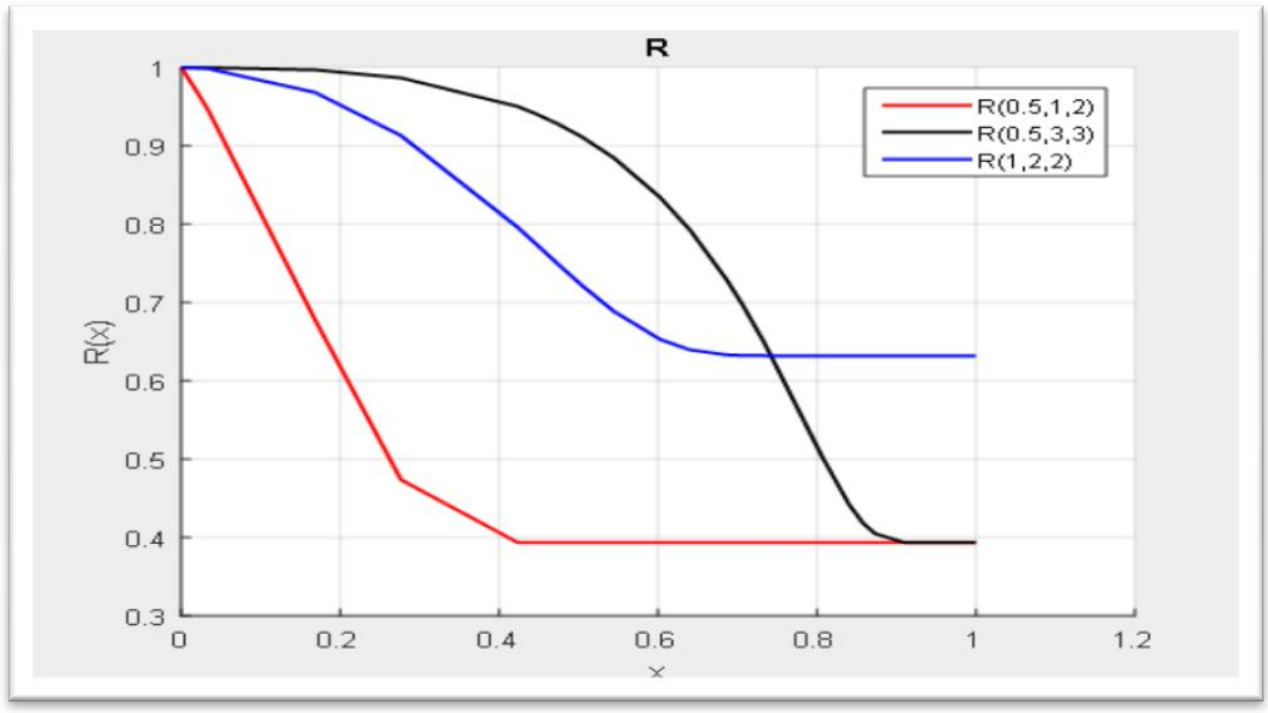

e - $\underline{\text { So }}$ if $\mathrm{x}$ is a mixture distribution (Exponential _ Kumaraswamy) distributed random variable, then: 


$$
\mathrm{E}(\mathrm{X})=\frac{\Gamma\left(\frac{j}{\beta}+1\right)}{\sum_{J=0}^{\infty} j^{\frac{2}{\alpha}+j-1} \lambda^{\frac{j}{\beta}}}
$$

$\operatorname{Var}(\mathrm{x})=\frac{\Gamma\left(\frac{j}{\beta}+1\right)}{\sum_{J=0}^{\infty} j^{\frac{2}{\alpha}+j-1} \lambda^{\frac{j}{\beta}}}-\left[\frac{\Gamma\left(\frac{j}{\beta}+1\right)}{\sum_{J=0}^{\infty} j^{\frac{1}{\alpha}+j-1}(\lambda)^{\frac{j}{\beta}}}\right]^{2}$

And

$E(x)^{r}=\int_{0}^{\infty} x^{r} F_{E-k}(x ; \alpha, B, \lambda) d x$

$\left.E(x)^{r}=(\alpha B \lambda) \int_{0}^{\infty}\left(1-x^{\alpha}\right)^{-B-1}\left(x^{r+\alpha-1}\right) e x p^{-e\left(\left(1-x^{\alpha}\right)^{-B}\right.}\right) d x$

Making the transformation

$$
\begin{aligned}
& \Gamma \alpha=\int_{0}^{\infty}(x)^{\alpha-1} e^{-y} d y \\
& E(\mathrm{x})^{\mathrm{r}}=k\left(\frac{1}{\lambda}\right)^{\frac{j}{\beta}} \Gamma\left(\frac{j}{\beta}+1\right)
\end{aligned}
$$

\section{6 - Maximum Likelihood Estimation}

Suppose $\mathrm{x}_{1}, \ldots, \mathrm{x}_{\mathrm{n}}$ is a random sample of size $\mathrm{n}$ from the Exp-K distribution given by (9) .The log-likelihood function for the vector of parameters $\varphi=(\mathrm{x} 1, \ldots \mathrm{xn} ; \alpha, \beta, \lambda)$ can be written as:

$$
\begin{gathered}
\log L \varphi\left(=n \ln \alpha+\operatorname{nln} \beta+n \ln e-(\beta+1)\left(\sum_{i=1}^{n} \log \left(1-x i^{\alpha}\right)\right)+(\alpha\right. \\
\left.-1) \sum_{i=1}^{n} \log (x i)(\lambda) \sum_{i=1}^{n} \log \left(1-x i^{\alpha}\right)^{-B}\right) \\
\frac{\partial \log l}{\partial \lambda}=\frac{n}{\lambda}-\sum_{i=1}^{n}\left(1-x_{i}^{\alpha}\right)^{-\beta} \\
\frac{\partial \log l}{\partial \beta}=\frac{n}{\beta}+\sum_{i=1}^{n} \log \left(1-x_{i}^{\alpha}\right)+\lambda \sum_{i=1}^{n}\left(1-x i^{\alpha}\right)^{-\beta}
\end{gathered}
$$

$\log \left(1-x_{i}^{\alpha}\right)(19)$

$\frac{\partial \log l}{\partial \alpha}=\frac{n}{\alpha} \sum \log x_{i}-(\beta+1) \sum_{i=1}^{n} \frac{1}{\left(1-x_{i}^{\alpha}\right)}\left(-x_{i}^{\alpha}\right)(1) \log \left(x_{i}^{\alpha}\right)+\lambda \beta \sum_{i=1}^{n}\left(1-x_{i}^{\alpha}\right)^{-\beta-1}\left(-x_{i}^{\alpha}\right)(1) \log x_{i}(20)$

From $\frac{\partial \log l}{\partial \alpha}=0$ this lead to

$\frac{n}{\hat{\alpha}}=-\sum \log x_{i}-(\beta+1) \sum_{i=1}^{n} \frac{x_{i}^{\alpha} \log x_{i}}{\left(1-x_{i}^{\alpha}\right)}+\lambda \beta \sum_{i=1}^{n}\left(1-x_{i}^{\alpha}\right)^{-\beta-1} x_{i}^{\alpha} \log x_{i}$

$$
\begin{aligned}
\hat{\alpha}_{M L E}= & \frac{n}{\lambda \beta\left(\sum_{i=1}^{n} \frac{x_{i}^{\alpha} \log x_{i}}{\left(1-x_{i}^{\alpha}\right)^{\beta+1}}\right)} \\
& =\frac{n}{-\sum \log x_{i}-(\beta+1) \sum_{i=1}^{n} \frac{x_{i}^{\alpha} \log x_{i}}{\left(1-x_{i}^{\alpha}\right)}}
\end{aligned}
$$

and from $\frac{\partial \log l}{\partial \lambda}=0$ 


$$
\begin{aligned}
\frac{n}{\hat{e}_{M L E}} & =\sum_{i=1}^{n}\left(1-x_{i}^{\alpha}\right)^{-\beta} \\
\hat{e}_{M L E} & =\frac{n}{\sum_{i=1}^{n}\left(1-x_{i}^{\alpha}\right)^{-\beta}}
\end{aligned}
$$

$$
\text { and } \begin{aligned}
\hat{\beta}_{M L E} & =\frac{n}{\sum_{i=1}^{n} \log \left(1-x_{i}^{\alpha}-\lambda\right)} \\
& =\frac{n}{\sum_{i=1}^{n}\left(1-x_{i}^{\alpha}\right)^{-\beta} \log \left(1-x_{i}^{\alpha}\right)}
\end{aligned}
$$

\section{7 - Discussion}

a - The study has used simulation for the purpose of comparing the different experimental methods. It is based on 50,75, 150 sample sizes and on different default values for the distribution parameters as shown in Table (1). The purpose of the study is to amine the best estimate.

$\mathrm{b}$ - In Table (2), the parameters assumed by experiment (1) were used and are shown in Table (1). X values are values generated from the default values of the experiment (1).

c - In Table (3), the parameters assumed by experiment (2) were used and illustrated in Table (1). X values are values generated from the default values of the experiment (2).

\begin{tabular}{|c|c|c|c|c|c|c|c|c|c|c|}
\hline \multirow[t]{2}{*}{$\mathbf{N}$} & \multirow[t]{2}{*}{ Method } & \multicolumn{3}{|c|}{ Experiment 1} & \multicolumn{3}{|c|}{ Experiment 2} & \multicolumn{3}{|c|}{ Experiment 3} \\
\hline & & $\begin{array}{l}\lambda \\
=0.7\end{array}$ & $\begin{array}{l}\text { B } \\
=0.3\end{array}$ & $\begin{array}{l}\alpha \\
=0.9\end{array}$ & $\lambda=1$ & $\begin{array}{l}\text { B } \\
=0.5\end{array}$ & $\alpha=1$ & $\begin{array}{l}\lambda \\
=1.5\end{array}$ & $\begin{array}{l}\text { B } \\
=1.2\end{array}$ & $\begin{array}{l}\alpha \\
=0.6\end{array}$ \\
\hline \multirow[t]{2}{*}{50} & Mle & 0.9352 & 0.3394 & 0.8280 & 1.4161 & 0.6572 & 0.6971 & 1.5755 & 1.2133 & 0.6224 \\
\hline & Mse-mle & 0.0587 & 0.0016 & 0.03274 & 0.2188 & 0.0324 & 0.3020 & 0.0054 & 0.0026 & 0.0033 \\
\hline \multirow[t]{2}{*}{75} & Mle & 0.8951 & 0.3404 & 0.8335 & 1.2836 & 0.7005 & 0.7677 & 1.5753 & 1.2122 & 0.6220 \\
\hline & Mse-mle & 0.0434 & 0.0016 & 0.03144 & 0.1082 & 0.0883 & 0.2982 & 0.0052 & 0.0022 & 0.0030 \\
\hline \multirow[t]{2}{*}{150} & Mle & 0.9389 & 0.3407 & 0.8535 & 1.3422 & 0.6114 & 0.8439 & 1.5750 & 1.2120 & 0.6210 \\
\hline & Mse-mle & 0.0605 & 0.0017 & 0.03004 & 0.1282 & 0.0169 & 0.0830 & 0.0051 & 0.0020 & 0.0020 \\
\hline
\end{tabular}

d - In Table (4), the parameters assumed by experiment (3) were used and illustrated in Table (1). X values are values generated from the default values of the experiment (3).

Table (1) : Estimates of the Parameters 
Table (2) : The values and mse of Reliability for the first experiment.

\begin{tabular}{|c|c|c|c|c|}
\hline \multirow[t]{2}{*}{$\mathbf{N}$} & \multirow[t]{2}{*}{$\mathbf{X}$} & \multirow[t]{2}{*}{ Rreal } & \multirow[t]{2}{*}{$\mathbf{R}_{\text {mle }}$} & Mse \\
\hline & & & & $\mathbf{R}_{\text {mle }}$ \\
\hline \multirow[t]{10}{*}{50} & 0.6079 & 0.7290 & 0.7000 & 0.0011 \\
\hline & 0.6389 & 0.6389 & 0.6028 & 0.0016 \\
\hline & 0.6801 & 0.5775 & 0.5380 & 0.0018 \\
\hline & 0.8164 & 0.5315 & 0.4902 & 0.0020 \\
\hline & 0.8471 & 0.4925 & 0.4502 & 0.0020 \\
\hline & 0.8759 & 0.4605 & 0.4179 & 0.0020 \\
\hline & 0.9341 & 0.4288 & 0.3862 & 0.0020 \\
\hline & 0.9818 & 0.4011 & 0.3589 & 0.0019 \\
\hline & 0.9966 & 0.3735 & 0.3320 & 0.0018 \\
\hline & 1.0279 & 0.3483 & 0.3076 & 0.0018 \\
\hline Mean - mse & & & & 0.0018 \\
\hline \multirow[t]{10}{*}{75} & 0.3797 & 0.7744 & 0.7547 & 0.0006 \\
\hline & 0.5802 & 0.6946 & 0.6691 & 0.0009 \\
\hline & 0.5916 & 0.6419 & 0.6135 & 0.0010 \\
\hline & 0.6966 & 0.6042 & 0.5739 & 0.0011 \\
\hline & 0.7024 & 0.5702 & 0.5385 & 0.0012 \\
\hline & 0.7117 & 0.5432 & 0.5107 & 0.0013 \\
\hline & 0.7337 & 0.5186 & 0.4855 & 0.0013 \\
\hline & 0.8205 & 0.4945 & 0.4609 & 0.0013 \\
\hline & 0.8256 & 0.4726 & 0.4388 & 0.0013 \\
\hline & 0.8332 & 0.4534 & 0.4193 & 0.0013 \\
\hline Mean - mse & & & & 0.0011 \\
\hline \multirow[t]{10}{*}{150} & 0.4662 & 0.8237 & 0.8111 & $0.2548 \mathrm{e}-003$ \\
\hline & 0.4977 & 0.7586 & 0.7422 & $0.4086 \mathrm{e}-003$ \\
\hline & 0.5131 & 0.7169 & 0.6982 & $0.5177 \mathrm{e}-003$ \\
\hline & 0.5301 & 0.6848 & 0.6645 & $0.5970 \mathrm{e}-003$ \\
\hline & 0.5478 & 0.6573 & 0.3657 & $0.6662 \mathrm{e}-003$ \\
\hline & 0.5904 & 0.6334 & 0.6009 & $0.7226 \mathrm{e}-003$ \\
\hline & 0.6176 & 0.6122 & 0.5888 & $0.7698 \mathrm{e}-003$ \\
\hline & 0.6533 & 0.5935 & 0.5694 & $0.8106 \mathrm{e}-003$ \\
\hline & 0.6552 & 0.5770 & 0.5523 & $0.8419 \mathrm{e}-003$ \\
\hline & 0.6645 & 0.5615 & 0.5364 & $0.8666 \mathrm{e}-003$ \\
\hline Mean - mse & & & & $6.4554 \mathrm{e}-004$ \\
\hline
\end{tabular}

The results have shown that the value of the reliability function decreases. 
Table (3) : The values and mse of Reliability for the second experiment.

\begin{tabular}{|c|c|c|c|c|}
\hline \multirow[t]{2}{*}{$\mathbf{N}$} & \multirow[t]{2}{*}{$\mathbf{X}$} & \multirow[t]{2}{*}{ Rreal } & \multirow[t]{2}{*}{$\mathbf{R}_{\text {mle }}$} & Mse \\
\hline & & & & $\mathbf{R}_{\text {mle }}$ \\
\hline \multirow[t]{10}{*}{50} & 0.5337 & 0.6967 & 0.7031 & 0.0007 \\
\hline & 0.5452 & 0.5953 & 0.6035 & 0.0011 \\
\hline & 0.5786 & 0.5341 & 0.5433 & 0.0013 \\
\hline & 0.6197 & 0.4825 & 0.4929 & 0.0014 \\
\hline & 0.6434 & 0.4409 & 0.4521 & 0.0015 \\
\hline & 0.6692 & 0.4062 & 0.4182 & 0.0016 \\
\hline & 0.7570 & 0.3758 & 0.3883 & 0.0016 \\
\hline & 0.8194 & 0.3457 & 0.3588 & 0.0016 \\
\hline & 0.8397 & 0.3197 & 0.3334 & 0.0016 \\
\hline & 0.8688 & 0.2939 & 0.3082 & 0.0016 \\
\hline Mean - mse & & & & 0.0014 \\
\hline \multirow[t]{10}{*}{75} & 0.2635 & 0.7466 & 0.7575 & 0.0005 \\
\hline & 0.3861 & 0.6587 & 0.6727 & 0.0008 \\
\hline & 0.3926 & 0.6000 & 0.6159 & 0.0009 \\
\hline & 0.3687 & 0.5565 & 0.5737 & 0.0011 \\
\hline & 0.6543 & 0.5204 & 0.5386 & 0.0012 \\
\hline & 0.7830 & 0.4891 & 0.5080 & 0.0012 \\
\hline & 0.8312 & 0.4623 & 0.4818 & 0.0013 \\
\hline & 0.8692 & 0.4400 & 0.4600 & 0.0013 \\
\hline & 0.9145 & 0.4183 & 0.4387 & 0.0014 \\
\hline & 0.9307 & 0.3982 & 0.4189 & 0.0014 \\
\hline Mean - mse & & & & 0.0011 \\
\hline \multirow[t]{10}{*}{150} & 0.2635 & 0.7985 & 0.8112 & 0.0003 \\
\hline & 0.3645 & 0.7284 & 0.7448 & 0.0005 \\
\hline & 0.3861 & 0.6795 & 0.6984 & 0.0006 \\
\hline & 0.3926 & 0.6435 & 0.6639 & 0.0007 \\
\hline & 0.4142 & 0.6140 & 0.6357 & 0.0008 \\
\hline & 0.5689 & 0.5892 & 0.6118 & 0.0009 \\
\hline & 0.5808 & 0.5669 & 0.5904 & 0.0009 \\
\hline & 0.6225 & 0.5479 & 0.5720 & 0.0010 \\
\hline & 0.6387 & 0.5302 & 0.5549 & 0.0010 \\
\hline & 0.6543 & 0.5137 & 0.5389 & 0.0011 \\
\hline Mean-mse & & & & $7.8219 \mathrm{e}-004$ \\
\hline
\end{tabular}

The results have shown that the value of the reliability function decreases. 
Table (4) : The values and mse of Reliability for the third experiment.

\begin{tabular}{|c|c|c|c|c|}
\hline \multirow[t]{2}{*}{$\mathbf{N}$} & \multirow[t]{2}{*}{$\mathbf{X}$} & \multirow[t]{2}{*}{ Rreal } & \multirow[t]{2}{*}{$\mathbf{R}_{\text {mle }}$} & Mse \\
\hline & & & & $\mathbf{R}_{\text {mle }}$ \\
\hline \multirow[t]{10}{*}{50} & 0.2603 & 0.7489 & 0.7057 & 0.0024 \\
\hline & 0.7477 & 0.6582 & 0.6038 & 0.0037 \\
\hline & 0.7805 & 0.6005 & 0.5409 & 0.0045 \\
\hline & 0.8213 & 0.5527 & 0.4897 & 0.0051 \\
\hline & 0.8377 & 0.5154 & 0.4505 & 0.0054 \\
\hline & 0.9505 & 0.4841 & 0.4183 & 0.0056 \\
\hline & 0.9626 & 0.4534 & 0.3872 & 0.0058 \\
\hline & 1.0299 & 0.4246 & 0.3885 & 0.0058 \\
\hline & 1.0383 & 0.3975 & 0.3318 & 0.0058 \\
\hline & 1.0385 & 0.3714 & 0.3066 & 0.0056 \\
\hline Mean-mse & & & & 0.0050 \\
\hline \multirow[t]{10}{*}{75} & 0.3750 & 0.7881 & 0.7553 & 0.0014 \\
\hline & 0.4612 & 0.7143 & 0.6727 & 0.0021 \\
\hline & 0.5139 & 0.6638 & 0.6172 & 0.0027 \\
\hline & 0.6130 & 0.6242 & 0.5741 & 0.0031 \\
\hline & 0.6806 & 0.5919 & 0.5394 & 0.0034 \\
\hline & 0.7020 & 0.5636 & 0.5094 & 0.0036 \\
\hline & 0.7021 & 0.5394 & 0.4840 & 0.0038 \\
\hline & 0.8084 & 0.5160 & 0.4595 & 0.0039 \\
\hline & 0.8321 & 0.4953 & 0.4382 & 0.0041 \\
\hline & 0.8467 & 0.4756 & 0.4180 & 0.0041 \\
\hline Mean-mse & & & & 0.0032 \\
\hline \multirow[t]{10}{*}{150} & 0.4135 & 0.8299 & 0.8071 & 0.0007 \\
\hline & 0.5292 & 0.7719 & 0.7424 & 0.0010 \\
\hline & 0.5536 & 0.7319 & 0.6982 & 0.0013 \\
\hline & 0.5966 & 0.7004 & 0.6637 & 0.0016 \\
\hline & 0.6074 & 0.6752 & 0.6362 & 0.0018 \\
\hline & 0.6208 & 0.6537 & 0.6130 & 0.0019 \\
\hline & 0.6307 & 0.6328 & 0.5905 & 0.0021 \\
\hline & 0.6548 & 0.6152 & 0.5717 & 0.0022 \\
\hline & 0.6579 & 0.5991 & 0.5546 & 0.0023 \\
\hline & 0.6604 & 0.5838 & 0.5383 & 0.0024 \\
\hline Mean-mse & & & & 0.0017 \\
\hline
\end{tabular}

The results have shown that the value of the reliability function decreases.

\section{8 - Conclusions}

a - Through the tables, the simulation results have shown that the mle method is the best method because it has achieved the least (mse) in all cases and for all sample sizes used in the study. $\mathrm{b}$ - The larger the samples size the smaller (mse).

$\mathrm{c}-\mathrm{We}$ have observed that the reliability function is a decreasing function, by the theoretical definition, the more the sample sizes increase the reliability decreases.

$\mathrm{d}$ - Composite distributions are better than other distributions. 


\section{References}

Adepoju, K.A., Chukwu, O.I. (2015) "Maximum Likelihood Estimation of the Kumaraswamy Exponential Distribution with Application " , Journal of Modern Applied Statistical Methods , vol.14 , no.1 , pp.( 208 -214 ).

AL- Bayaty, KH. N. J. (2012)" Comparison Between Methods Estimator Reliability Function of A Mixture Exponential Distribution With A practical Application “, Dissertation, Administration \& Economic College, University of Baghdad.

AL-Dariei ,M. A., (2016), "Some Methods Of Estimation Parameter Reliability Function Of The Probability Model Compound With Practical Application "Master of Science in Statistics ,To College of Administration \& Economics - University of Baghdad.( in Arabic ).

AL-Kadim .k. A. and .Boshi. M. A. (2013) "Exponential -Pareto Distribution" , Mathematical Theory and Modeling., Vol .3, No.5, pp.135-146.

AL-Saaray, A. H. Y., (2011)" A Comparison Between Bayes Approach and Maximum Likelihood Method to Estimate Reliability Function for Series System and Parallel System With Application", Master of Sciences In Statistics, To College of Administration \& Economics, University of Baghdad,( in Arabic ).

Akinsete , A., Famoye , F. \& Lee , C. ( 2014 ) " The Kumaraswamy - Geometric Distribution " , Journal of Statistical Distributions and Application, pp. $(1-17)$.

Barreto , S.W , Santos.A.H.S; and Cordeiro.G.M., (2009)" The beta generalized exponential distribution", Statistics.Vol.42.No.6.PP.547-563 .

Cordeiro, G.M, Ortego, E.M.M. and Nadarajah, S. ( 2010 ) " The Kumaraswamy Weibull Distribution with Application to failure data ", Journal of the Franklin Institute , no. 347 , pp. ( $1399-1429$ ) .

Cordeiro, G.M., Nadarajah, S. and Ortega, E.M.M. ( 2012 ) " The Kumaraswamy Gumbel Distribution " , Journal of Statistical Methods \& Applications, vol. 21 , no. 2 ,pp. ( $139-168$ ).

de Pascoa, M.A.R., Ortega, E.M.M. and Cordeiro, G.M. ( 2011 ) " The Kumaraswamy generalized gamma distribution with application in survival analysis ", Statistical Methodology, vol. 8 , pp. ( $411-433$ ) .

Gopta , R.D., Kundu,D. ( 1999 ) " Theory \& Methods : Generalized exponential distribution " , Australian and New Zealand Journal of Statistics, 41(2), pp. ( $173-188)$.

Jones, M.C. ( 2009 ) " Kumaraswamy distribution: A beta - type distribution with some tractability advantages " , Statistical Methodology , 6(1): 70-81 .

Lemonte, A.J. ( 2011 ) " Improved point estimation for the Kumaraswamy distribution " , Journal of Statistical Computation and Simulation, 81(12): $1971-1982$.

Lemonte, A.J., Barreto-Souza, W. and Cordeiro, M.G. (2013) " The exponential Kumaraswamy distribution and its log-transform ", Brazilian Journal of Probability and Statistics, vol. 27 , no.1.

Nassar,M. \& Fathy, H.E., (2003) " On the exponentiated Weibull distribution '", Communication and StatisticsTheory and Methods, Vol.33.

Rodrigues \& Silve, (2015), "The Exponentiated Kumaraswamy- Exponential Distribution", British Journal of Applied Science \& Technology, 10(5): 1-12, 2015, Article ISSN: 2231-0843. 